\title{
LX-04 VIOLENCE MEASUREMENTS- STEVEN TESTS IMPACTED BY PROJECTILES SHOT FROM A HOWITZER GUN
}

Steven K. Chidester, Kevin S. Vandersall, Lori L. Switzer, Craig M. Tarver

July 22, 2005

American Physical Society Meeting on Shock Compression of Condensed Matter Baltimore, MD, United States July 31, 2005 through August 5, 2005 
This document was prepared as an account of work sponsored by an agency of the United States government. Neither the United States government nor Lawrence Livermore National Security, LLC, nor any of their employees makes any warranty, expressed or implied, or assumes any legal liability or responsibility for the accuracy, completeness, or usefulness of any information, apparatus, product, or process disclosed, or represents that its use would not infringe privately owned rights. Reference herein to any specific commercial product, process, or service by trade name, trademark, manufacturer, or otherwise does not necessarily constitute or imply its endorsement, recommendation, or favoring by the United States government or Lawrence Livermore National Security, LLC. The views and opinions of authors expressed herein do not necessarily state or reflect those of the United States government or Lawrence Livermore National Security, LLC, and shall not be used for advertising or product endorsement purposes. 


\title{
LX-04 VIOLENCE MEASUREMENTS-STEVEN TESTS IMPACTED BY PROJECTILES SHOT FROM A HOWITZER GUN
}

\author{
Steven K. Chidester, Kevin S. Vandersall, Lori L. Switzer, and Craig M. Tarver \\ Lawrence Livermore National Laboratory \\ Livermore, CA 94550
}

\begin{abstract}
Characterization of the reaction violence of LX-04 explosive (85\% HMX and 15\% Viton A by weight) was obtained from Steven Impact Tests performed above the reaction initiation threshold. A $155 \mathrm{~mm}$ Howitzer propellant driven gas gun was used to accelerate the Steven Test projectiles in the range of approximately $170-300 \mathrm{~m} / \mathrm{s}$ to react (ignite) the LX-04 explosive. Blast overpressure gauges, acoustic microphones, and high-speed photography characterized the level of high explosive reaction violence. A detonation in this velocity range was not observed and when comparing these results (and the Susan test results) with that of other HMX based explosives, LX-04 has a more gradual reaction violence slope as the impact velocity increases. The high binder content (15\%) of the LX-04 explosive is believed to be the key factor to the lower level of violence.
\end{abstract}

Keywords: Steven Impact Test, Explosive safety, LX-04, HMX explosives, ignition threshold PACS: $82.33 . V x, 82.40 . F p$

\section{INTRODUCTION}

In general, the Steven Impact Test is a safety test involving high explosive (HE) targets impacted at increasingly greater velocities with projectiles until you get a "GO" (reaction). For the most part, these reactions involve a burning or deflagration process in lieu of a full-scale detonation. Naturally, the lowest velocity where you get a "GO" is the "reaction threshold" and typically involves several experiments to determine. Performing experiments above the "reaction threshold" as presented in this work can also act to characterize the level of violence observed in the reaction. Both the "reaction threshold" and violence level data can be utilized in various hydrodynamic reactive flow models for safety predictions that may not be directly tested.
Research on the Steven Test has been performed at Lawrence Livermore National Laboratory [1-7] as well as a modified version of this test at Los Alamos National Laboratory [8-10]. Converting overpressure transit data from impact to equivalent point source energy dates back to the Susan Test [11] and is discussed in a prior publication [12].

The Steven Impact Test results to date have increased the fundamental knowledge and practical predictions of impact safety hazards for confined and unconfined explosive charges. As discussed in the prior publications [1-10], friction, shear, and strain are the main contributing mechanisms to reaction although continuing research is still investigating these individual areas and combinations of mechanisms. 


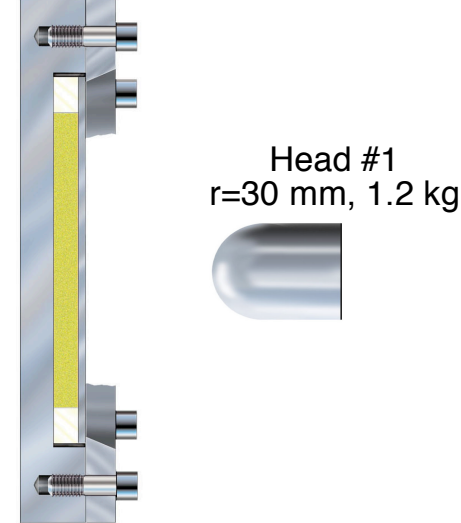

FIGURE 1. Schematic diagram of the standard Steven Impact Test arrangement used in this work.

\section{EXPERIMENTAL PROCEDURE}

For these experiments, a $155 \mathrm{~mm}$ diameter smooth bore Howitzer gun located at LLNL Site 300 , bunker 850 was utilized to fire five projectiles with various velocities at Steven Impact Test targets on an outdoor firing table. The experimental geometry of the Steven Impact Test target is shown in Fig. 1. The steel projectile head (see Fig. 1) is attached to a sabot body that is accelerated via a propellant charge into the target. External blast overpressure gauges were placed around the target at a $3.05 \mathrm{~m}$ standoff for direct comparison to the Susan test data [11].

This work was performed using LX-04 (85\% HMX, 15\% Viton A) energetic material samples to determine if the gradual reaction violence slope continues as the impact velocity increases. Normally a $76 \mathrm{~mm}$ diameter smooth bore light gas gun is used for these tests, but the Howitzer gun was used instead due to a higher velocity capability.

As shown in Fig. 1, the projectile consists of a hemispherical $30.05 \mathrm{~mm}$ radius steel head having a mass of $1.2 \mathrm{~kg}$. The test projectile is accelerated into a $110 \mathrm{~mm}$ diameter by 12.85 $\mathrm{mm}$ thick explosive charge confined by a 3.18 $\mathrm{mm}$ thick steel plate on the impact face, a 19.05 $\mathrm{mm}$ thick steel plate on the rear surface, and $26.7 \mathrm{~mm}$ thick steel side confinement. A Teflon ring around the explosive provides radial confinement. Blast overpressure gauges, microphones, and high-speed photography characterized the level of reaction violence.

\section{RESULTS/DISCUSSION}

The tabulated results for this work are shown in Table 1. Included are details about the experiment number, impact velocity, and reaction violence. All of these tests were performed at ambient temperature $\left(20^{\circ} \mathrm{C}\right)$ using LX-04 as the target material with 277 -month stockpile age and had a sample density of 1.863 $\mathrm{g} / \mathrm{cm}^{3}$. The reaction violence was obtained by converting the measured over-pressures to grams of TNT equivalent reaction [12].

The test results were video taped with fast framing cameras. Two of the frames from a test are presented in Figures 2 and 3. The grid in the background of the movie frames is used as a conformation of the projectile velocity. The visual evidence obtained by the movies helps provide a rough correlation of the over-pressure gauge results. The reaction observed is clearly not a detonation and this is confirmed by the over-pressure gauge results. Intentional detonations with TNT and other explosives were reported previously [3].

TABLE 1. Summary of LX-04 (sample density 1.863 $\mathrm{g} / \mathrm{cm}^{3}$ ) high velocity Steven Test results performed at ambient temperature $\left(20^{\circ} \mathrm{C}\right)$.

\begin{tabular}{|c|c|c|}
\hline EXPT & $\begin{array}{c}\text { PROJECTILE } \\
\text { VELOCITY } \\
\mathrm{m} / \mathrm{s},(\mathrm{ft} / \mathrm{s})\end{array}$ & $\begin{array}{c}\text { VIOLENCE-TNT } \\
\text { EQUIVALENT } \\
(\mathrm{g})\end{array}$ \\
\hline WRL158 & $173,(569)$ & 160 \\
\hline WRL157 & $231,(759)$ & 154 \\
\hline WRL156 & $250,(820)$ & 180 \\
\hline WRL155 & $293,(961)$ & 185 \\
\hline WRL154 & $298,(979)$ & 175 \\
\hline
\end{tabular}




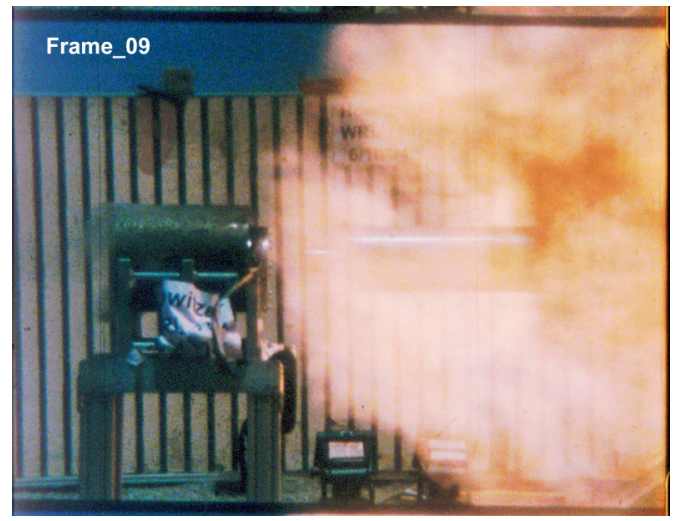

FIGURE 2. Frame showing projectile prior to projectile impact.

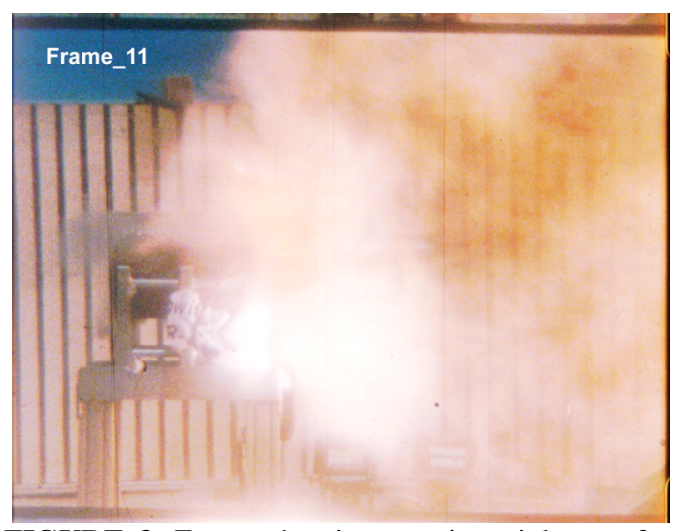

FIGURE 3. Frame showing reaction violence after projectile impact.

Figure 4 presents a comparison of results for the Steven Impact Test (dashed lines) and the Susan Impact test (solid lines) regarding the reaction violence in the form of blast overpressure related to a TNT equivalent as a function of the projectile velocity. All five tests with the Howitzer gun with velocities ranging from 173 to $298 \mathrm{~m} / \mathrm{s}$ had about the same reaction violence with no noticeable trend.

There is good reaction violence correlation between the Steven Tests and the Susan Tests in order of decreasing explosive reaction violence PBX 9404, LX-10, PBX 9501, and LX-04. The five recent Steven Tests reported here with LX-
04 do not follow the gradually increasing violence trend of the Susan Test. A possible explanation for this is that in the Susan test the explosive sample may remain under inertial confinement between the Susan projectile and the impact barrier longer than does the explosive in the Steven test geometry. This longer confinement duration could allow the ignited LX-04 to react gradually more violently in the Susan Test as the velocity increases. This postulated explanation could be tested in future three-dimensional hydrodynamic modeling and experiments using increased confinement of the LX-04 Steven Test charges.

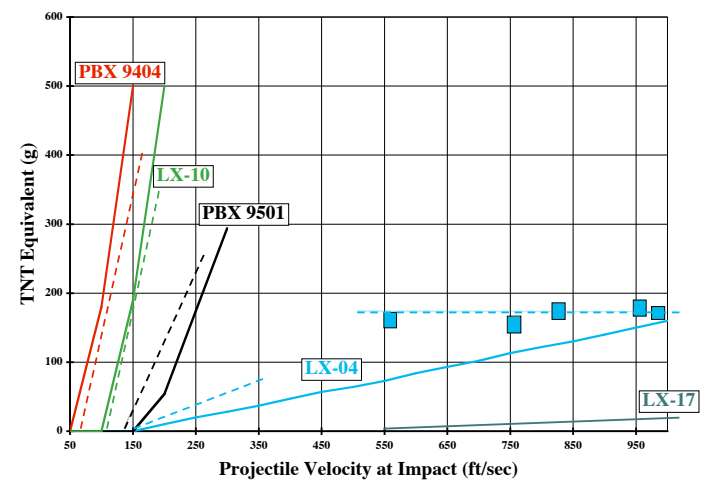

FIGURE 4. Comparison of results for the Steven Impact Test (dashed lines) and the Susan Impact test comparing violence in the form of blast overpressure related to a TNT equivalent as a function of the projectile velocity.

\section{SUMMARY AND FUTURE WORK}

Steven Test targets containing LX-04 explosive samples were impacted at velocities up to $298 \mathrm{~m} / \mathrm{s}$. In comparing these results to those for LX-04 from the Susan Test, the LX-04 reaction violence did not gradually continue to increase as previously predicted. All five tests with the Howitzer gun with velocities ranging from 173 to $298 \mathrm{~m} / \mathrm{s}$ had about the same reaction violence with no noticeable trend although an asymptote may have been reached. 
Future work is planned to incorporate these Steven Test reaction violence results into $\mathrm{HE}$ reactive flow computer models for LX-04 that can then be used to make reaction violence predictions for other impact scenarios and for LX-04 in other geometries.

\section{ACKNOWLEDGEMENTS}

The following members of the $155 \mathrm{~mm}$ gun crew at Site 300 (Bunker 850) are thanked for their hard work: Karen Luis, Tommy Rambur, Jim Browning, and Anthony Regalado. In addition, this work would not have been possible without the unwavering management and funding provided by Ron Streit. This work was performed under the auspices of the U. S. Department of Energy by the University of California, Lawrence Livermore National Laboratory under Contract No. W-7405-Eng48.

\section{REFERENCES}

1. Chidester, S.K., Green, L.G., and Lee, C.G., "A Frictional Work Predictive Method for the Initiation of Solid High Explosives from Low Pressure Impacts," Tenth International Detonation Symposium, ONR 33395-12, Boston, MA 1993, pp. 785-792.

2. Chidester, S. K., Tarver, C. M., and Lee, C. G., "Impact Ignition of New and Aged Solid Explosives," Shock Compression of Condensed Matter-1997, edited by S.C. Schmidt et. al., AIP Conference Proceedings 429, AIP Press, New York, 1998, pp. 707-710.

3. Chidester, S. K., Tarver, C. M., and Garza, R., “ Low Amplitude Impact Testing and Analysis of Pristine and Aged Solid High Explosives," Eleventh (International) Symposium on Detonation, ONR 33300-5, Arlington, VA, 1998, pp. 93-100.

4. Chidester, S. K., Tarver, C. M., DePiero, A. H., and Garza, R. G., "Single and Multiple Impact of New and Aged High Explosives in the Steven Impact Test," Shock Compression of Condensed Matter-1999, M.D. Furnish, L. C. Chhabildas, and R. S. Hixson, eds., AIP Conference Proceedings 505, New York, 2000, P. 663-666.
5. Niles, A. M., Garcia, F., Greenwood, D. W., Forbes, J. W., Tarver, C. M., Chidester, S. K., Garza, R. G., and Switzer, L. L., "Measurement of Low Level Explosives Reaction in Gauged Multi-dimensional Steven Impact Tests," Shock Compression of Condensed Matter-2001, Furnish, M. D., Thadhani, N. N., and Horie, Y, eds. CP-620, AIP Press, New York, (2002).

6. Vandersall, K.S., Chidester, S. K., Forbes, J. W., Garcia, F., Greenwood, D. W., Switzer, L. L., and Tarver, C. M., "Experimental and Modeling Studies of Crush, Puncture, and Perforation Scenarios in the Steven Impact Test," Proceedings of the 12th International Detonation Symposium, San Diego, CA, August, 2002, pp.131-139.

7. Switzer, L. L., Vandersall, K. S., Chidester, S. K., Greenwood, D. W., and Tarver, C. M., "Threshold Studies of Heated HMX-Based Energetic Material Targets Using the Steven Impact Test," Shock Compression of Condensed Matter-2003, edited by M.D. Furnish, Y.M. Gupta, and J.W. Forbes, pp. 1045-1048, 2004.

8. Idar, D. J., Lucht, R. A., Straight, J. W., Scammon, R. J., Browning, R. V., Middleditch J., Dienes, J. K., Skidmore, C. B., and Buntain, G. A., "Low Amplitude Insult Project: PBX9501 High Explosive Violent Reaction Experiments," Eleventh International Detonation Symposium, Aspen, CO, 1998, pp. 101-110.

9. Scammon, R. J., Browning, R. V., Middleditch, J., Dienes, J. K. Haverman, K. S., and Bennett, J. G., "Low Amplitude Insult Project: Structural Analysis and Prediction of Low Order Reaction," Eleventh International Detonation Symposium, Aspen, CO, 1998, pp. 111-118.

10. Browning, R. V., "Microstructural model of mechanical initiation of energetic materials," Shock Compression of Condensed Matter-1995, S. C. Schmidt and W. C. Tao, eds, AIP Press, New York, 1996, p. 405-408.

11. Dobratz, B.M. and Crawford, P.C., LLNL Explosives Handbook, Lawrence Livermore National Laboratory Report UCRL-52997 change 2, 1985.

12. Green, L.G. and Dorough, G.D., "Further studies on the Ignition of Explosives, Fourth Symposium (International) on Detonation, October 12-15, 1965, White Oak, MD, pp. 477-486. 